Check for updates

Cite this: RSC Adv., 2018, 8, 32231

\title{
From grass to battery anode: agricultural biomass hemp-derived carbon for lithium storage $\uparrow$
}

\author{
Ji Hyun Um, ${ }^{a}$ Chi-Yeong Ahn, (DD bc Jinsoo Kim, ${ }^{\text {d }}$ Mihee Jeong, ${ }^{a}$ Yung-Eun Sung, (D) bc \\ Yong-Hun Cho, ${ }^{* e}$ Seung-Soo Kim ${ }^{* f}$ and Won-Sub Yoon (D) *a
}

Biomass-derived carbon, as a low-cost material source, is an attractive choice to prepare carbon materials, thus providing an alternative to by-product and waste management. Herein, we report the preparation of carbon from hemp stem as a biomass precursor through a simple, low-cost, and environment-friendly method with using steam as the activating agent. The hemp-derived carbon with a hierarchically porous structure and a partial graphitization in amorphous domains was developed, and for the first time, it was applied as an anode material for lithium-ion battery. Natural hemp itself delivers a reversible capacity of $190 \mathrm{~mA} \mathrm{~h} \mathrm{~g} \mathrm{~g}^{-1}$ at a rate of $300 \mathrm{~mA} \mathrm{~g}^{-1}$ after 100 cycles. Ball-milling of hemp-derived carbon is further designed to control the physical properties, and consequently, the capacity of milled hemp increases to $300 \mathrm{~mA} \mathrm{~h} \mathrm{~g}{ }^{-1}$ along with excellent rate capability of $210 \mathrm{~mA} \mathrm{~h} \mathrm{~g}{ }^{-1}$ even at $1.5 \mathrm{~A} \mathrm{~g}^{-1}$. The milled hemp with increased graphitization and welldeveloped meso-porosity is advantageous for lithium diffusion, thus enhancing electrochemical performance via both diffusion-controlled intercalation/deintercalation and surface-limited adsorption/desorption. This study not only demonstrates the application of hemp-derived carbon in energy storage devices, but also guides a desirable structural design for lithium storage and transport.

Received 20th August 2018 Accepted 3rd September 2018

DOI: $10.1039 / \mathrm{c} 8 \mathrm{ra06958a}$

rsc.li/rsc-advances
Carbon materials are being developed from various biomasses (as carbonaceous precursors) and regarded as an attractive choice due to at least two reasons: the biomass-derived carbons provide an alternative for by-product and waste management, and the naturally available raw materials are an economic choice for material engineering. ${ }^{5,6}$ In particular, agricultural waste biomass has proved to be a promising raw material for the preparation of carbon over the last twenty years. ${ }^{7}$ Biomass-derived carbons can have intrinsically desirable molecular structures for charge storage and transport and therefore, they often deliver higher capacity than graphite with the intrinsically desirable molecular structures. ${ }^{5,6}$ Activation of carbonaceous materials with a considerably fibrous structure, such as cellulose and hemicellulose, is easier than activation of those with a less fibrous structure. Simultaneously, higher proportion of lignin in cellulose and hemicellulose has a more labile and a less robust nature compared with lignin alone. ${ }^{89}$ The large amount of oxygencontaining functional groups in cellulose and hemicellulose easily transform into $\mathrm{H}_{2} \mathrm{O}$, $\mathrm{CO}$ and $\mathrm{CO}_{2}$, producing micropores during pyrolysis, while the rich aromatic functional groups in lignin are chemically inert, resulting in nonporous carbon. ${ }^{\mathbf{1 0 , 1 1}}$ Therefore, it is generally agreed that, in the biomass-derived carbons, the pore structure and pore size distribution is mostly dependent on the nature of starting material. ${ }^{12-15}$

Hemp (Cannabis sativa L.) is being cultivated for centuries as a useful grass plant with historical applications from the source of ancient fiber for rope, sails, and clothing to its current use, such as in paper, textiles, food, building materials, medicine, \footnotetext{
South Korea. E-mail: sskim2008@kangwon.ac.kr

$\dagger$ Electronic supplementary information (ESI) available. See DOI: 10.1039/c8ra06958a

Department of Energy Science, Sungkyunkwan University, Suwon 16419, South Korea ${ }^{b}$ School of Chemical and Biological Engineering, Seoul National University, Seoul 08826, South Korea Korea

${ }^{d}$ Department of Chemical Engineering, Kyung Hee University, Yongin 17104, South Korea

${ }^{e}$ Division of Energy Engineering, Kangwon National University, Samcheok 25913, South Korea. E-mail: yhunoo@kangwon.ac.kr

Department of Chemical Engineering, Kangwon National University, Samcheok 25913,
} 
detergent, ink, oil, and fuel, which enables hemp to have an important industrial value. ${ }^{16,17}$ Moreover, hemp grows quickly in most climates and locations without any special requirements for sunshine, water, fertilizer, and pesticides, thus becoming an economical and environment-friendly crop. ${ }^{\mathbf{1 6 , 1 7}}$ Particularly, for the hemp stem, the by-products such as leaf, stem, and roots are rich in cellulose and hemicellulose with a low content of lignin; thus, along with its low-cost and environment protection, these features make the hemp stem an attractive precursor to obtain the biomass-derived carbon. In the hemp stem, the content of cellulose and hemicellulose is $58-72 \%$ and $66-91 \%$ in woody core and bast fibers, respectively. ${ }^{18}$ Indeed, hemp-derived carbons with high surface areas up to $2287 \mathrm{~m}^{2} \mathrm{~g}^{-1}$ (ref. 19) and well-developed mesopores were obtained using activation agents such as water, $\mathrm{ZnCl}_{2}$, and $\mathrm{H}_{3} \mathrm{PO}_{4} \cdot{ }^{17,20,21}$ They were applied as an adsorbent for water vapor, ${ }^{17}$ as a catalyst for glycolysis of poly(ethylene terephthalate) (PET), ${ }^{22}$ and as an electrode of supercapacitors. ${ }^{19,23}$ For a carbon anode for LIB, effects of pore structure and pore size distribution on its performance emphasize the development of hierarchically porous structure consisting of micro-, meso-, and macro-pores. ${ }^{24}$ It is demonstrated that mesoporosity with a dual pore-sized system is advantageous for obtaining reversible and high capacity because the micro-pores in electrode are prone to clogging by the growth of solid electrolyte interface (SEI) layer and other side reactions, which causes hindrance to electrolyte transport into pores and capacity loss upon cycling. ${ }^{25,26}$

Herein, we prepared carbon from hemp stem as a biomass precursor through a simple, low-cost, and environment-friendly method by physical activation using only steam. The partially graphitic carbon with a hierarchically porous structure is developed in the hemp-derived carbon. Moreover, for the first time, this hemp-derived carbon was directly applied as an anode material for LIB. Ball-milling processing of the hempderived carbon can further control its physical properties, such as crystallinity and porosity. Compared with natural hemp, the increased crystallinity and well-developed mesoporosity in milled hemp are favorable for lithium diffusion. Consequently, enhanced electrochemical performance occurs in both diffusion-controlled intercalation/deintercalation and surfacelimited adsorption/desorption. This study explores the potential of hemp for utilization in lithium storage and transport, and demonstrates that hemp-derived carbon can be a nextgeneration carbon material for LIB anode.

\section{Experimental}

\section{Preparation of hemp-derived carbon}

Hemp stem was used as the starting biomass for obtaining a carbon material. A section of hemp stem was ground with a knife mill into particles sized less than $1.5 \mathrm{~mm}$ and dried at room temperature for $24 \mathrm{~h}$. Fig. S1 $\uparrow$ depicts the schematic of a tubular pyrolysis reactor used in this study. A quartz tube reactor (length: $800 \mathrm{~mm}$, inner diameter: $55 \mathrm{~mm}$, outer diameter: $60 \mathrm{~mm}$ ) was set up vertically inside a tubular furnace. For each run, $5 \mathrm{~g}$ of hemp stem was placed in a basket made of a stainless steel wire net (60 meshes), which was then placed in center of the tube reactor. The hemp stem was carbonized under continuous $\mathrm{N}_{2}$ gas flow at $200 \mathrm{~cm}^{3} \mathrm{STP} \mathrm{min}^{-1}$. The carbonization temperature of $800{ }^{\circ} \mathrm{C}$ was achieved at a heating rate of $10{ }^{\circ} \mathrm{C} \mathrm{min}^{-1}$ and maintained for $2 \mathrm{~h}$. For the activation process, $300 \mathrm{~cm}^{3} \mathrm{STP} \mathrm{min}^{-1}$ of $\mathrm{N}_{2}$ gas was continuously fed into the reactor; at the same time, steam was used as an activation agent. Under the steam flow rate of $2 \mathrm{~mL} \mathrm{H}_{2} \mathrm{O} \mathrm{g}$-char ${ }^{-1} \mathrm{~h}^{-1}$, the activation process was conducted at $800{ }^{\circ} \mathrm{C}$ for $2 \mathrm{~h}$. After activation, the sample was cooled inside the furnace under $\mathrm{N}_{2}$ gas flow to prevent oxidation, and the obtained carbon was referred to as natural hemp in this study.

To control the physical properties of the obtained carbon powder, a ball-milling process on the hemp-derived carbon was employed in this study. The hemp-derived carbon was ballmilled at room temperature, during which $0.32 \mathrm{~g}$ of the natural hemp powder and steel balls with the mass ratio of $1: 9.1$ were placed into a milling apparatus and rotated for $1 \mathrm{~h}$; the obtained carbon powder was referred to as milled hemp.

\section{Materials characterization}

Moisture and ash contents of the hemp stem were determined by ASTM E1756 and ASTEM E1755, respectively, while complying with the standard tests for ash in biomass. Inorganic composition of the sample was analyzed by inductively coupled plasma-mass spectrometry (ICP-MS, Ultramass-700, Varian, USA). BET surface area and porosity of the hemp-derived carbon were measured by the $\mathrm{N}_{2}$ adsorption/desorption isotherms at $-196{ }^{\circ} \mathrm{C}$ and the Barrett-Joyner-Halenda (BJH) method, respectively, on a Micromeritics ASAP 2420. Pore size distribution and porosity of the hemp-derived carbon were also analyzed using mercury intrusion porosimetry (AutoPore IV 9510, Micromeritics). XRD patterns were obtained on a Bruker $\mathrm{D}-5005$ using $\mathrm{Cu}-\mathrm{K} \alpha$ radiation $(\lambda=1.5406 \AA)$, operating at $40 \mathrm{kV}$ and $40 \mathrm{~mA}$ with a scan range of $15-75^{\circ}$. Morphologies of sample were observed using scanning electron microscopy (SEM, JSM5410, JEOL), field emission scanning electron microscopy (FESEM, Carl Zeiss, SUPRA 55VP), and transmission electron microscopy (TEM, JEOL JEM-2100F). C K-edge soft X-ray absorption spectroscopy (XAS) measurement was performed the 10D-KIST beamline using Pohang Light Source-II (PLS-II). All of the spectra were collected in total electron yield (TEY) mode and fluorescence yield (FY) mode simultaneously under a base pressure of $3 \times 10^{-10}$ torr with $0.1 \mathrm{eV}$ energy resolution. These spectra were normalized to the incident photon flux.

\section{Electrochemical measurements}

Because carbon was obtained as a chip-shaped reaction product after the activation process, it was milled by hand in a mortar for $1 \mathrm{~h}$ to form a powder. The working electrode was fabricated by mixing the hemp-derived carbon powder as an active material, PVDF as a binder, and Super $\mathrm{P}$ as a conductive agent in a weight ratio of $70: 15: 15$ in $N$-methyl-2-pyrrolidone solvent. The mixed slurry was plastered onto a copper foil current collector uniformly through doctor blade processing, and then dried under vacuum at $120{ }^{\circ} \mathrm{C}$ for $8 \mathrm{~h}$. The dried slurry was 
punched to a size of $11 \mathrm{~mm}$ in diameter to match the electrode size. A 2032 type coin cell, consisting of the working electrode and lithium metal as both a counter and a reference electrode was assembled in a glove box under a dry argon atmosphere. The organic electrolyte used was $1 \mathrm{M} \mathrm{LiPF}_{6}$ dissolved in a mixture of ethylene carbonate (EC) and diethyl carbonate (DEC) (volume ratio of $1: 1$ ). Galvanostatic discharge/charge measurements (WBCS3000, Wonatech) were performed on the coin cell in the voltage range of $3 \mathrm{~V}$ to $0.01 \mathrm{~V}\left(v s\right.$. $\left.\mathrm{Li}^{+} / \mathrm{Li}\right)$ at various current densities. Cyclic voltammetry (CV) was also performed on the Wonatech WBCS3000 workstation at a scan rate of $0.05 \mathrm{mV} \mathrm{s}^{-1}$ in the voltage range of $3-0.01 \mathrm{~V}\left(v s . \mathrm{Li}^{+} / \mathrm{Li}\right)$. Electrochemical tests were conducted at the constant room temperature of $25{ }^{\circ} \mathrm{C}$. Galvanostatic intermittent titration technique (GITT) was performed during the first discharge and charge processes at a constant current flux of $30 \mathrm{~mA} \mathrm{~g}^{-1}$ for an interval of $15 \mathrm{~min}$, followed by an open-circuit condition of $3 \mathrm{~h}$ to attain steady state equilibrium voltage $\left(E_{\mathrm{s}}\right)$ of the cell.

\section{Results and discussion}

A hemp field from where the hemp stem was harvested as one of the by-products is shown in the photograph in Fig. 1a, with the illustration of hemp-derived carbon as the host material for lithium storage. As described in the experimental section, hemp stem was ground with a knife mill into smaller particles (less than $1.5 \mathrm{~mm}$ ) in a chip-like form that is maintained after the activation process (Fig. 1b). As illustrated in Fig. 1c, during activation, steam flows in the reactor along the vertical direction to form an inter-connected pore network in the carbon, with hierarchically porous carbon consisting of micro-, meso-, and macro-pores, which were further investigated.

FE-SEM images (Fig. 2a-c) show the morphologies of carbon after activation process. As shown in Fig. 2a, at higher magnification than that shown in Fig. 1b, the structure of the chipshaped carbon is observed as a bundle of pores of $c a .10 \mu \mathrm{m}$ in diameter, which results from the primary flow of steam in the reactor, as indicated by the blue arrow. The interior morphology of carbon shown in Fig. 2b seems to be a xylem structure composed of vessel elements that transport water and minerals from roots to all other parts of the plant; such vessels are hollow with no contents and separated by the carbon wall. ${ }^{27}$ It can be considered that steam passing through the carbon interior enables carbon to have this channel-like form with a hollow structure. Along with the channel-shaped pores (blue box I, Fig. 2c), the steam flow vertical to the main stream is reflected

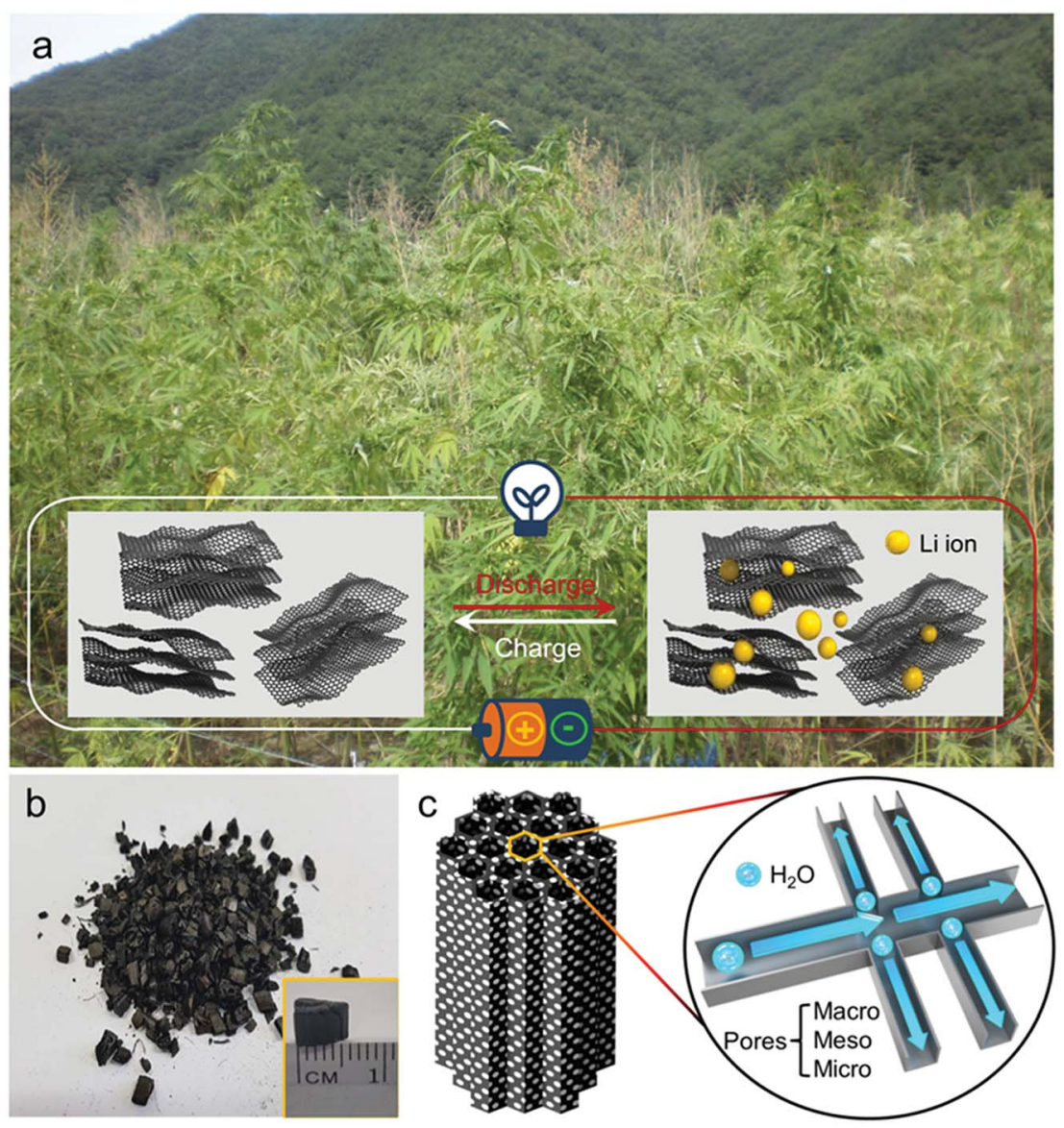

Fig. 1 Natural hemp and its application in LIB. (a) Photograph of hemp field and schematic illustration of lithium storage in hemp-derived carbon material. (b) Photograph of chip-shaped reaction product after activation. Inset image shows the scale of individual chip. (c) Schematic of hierarchically porous carbon structure in hemp-derived carbon. 

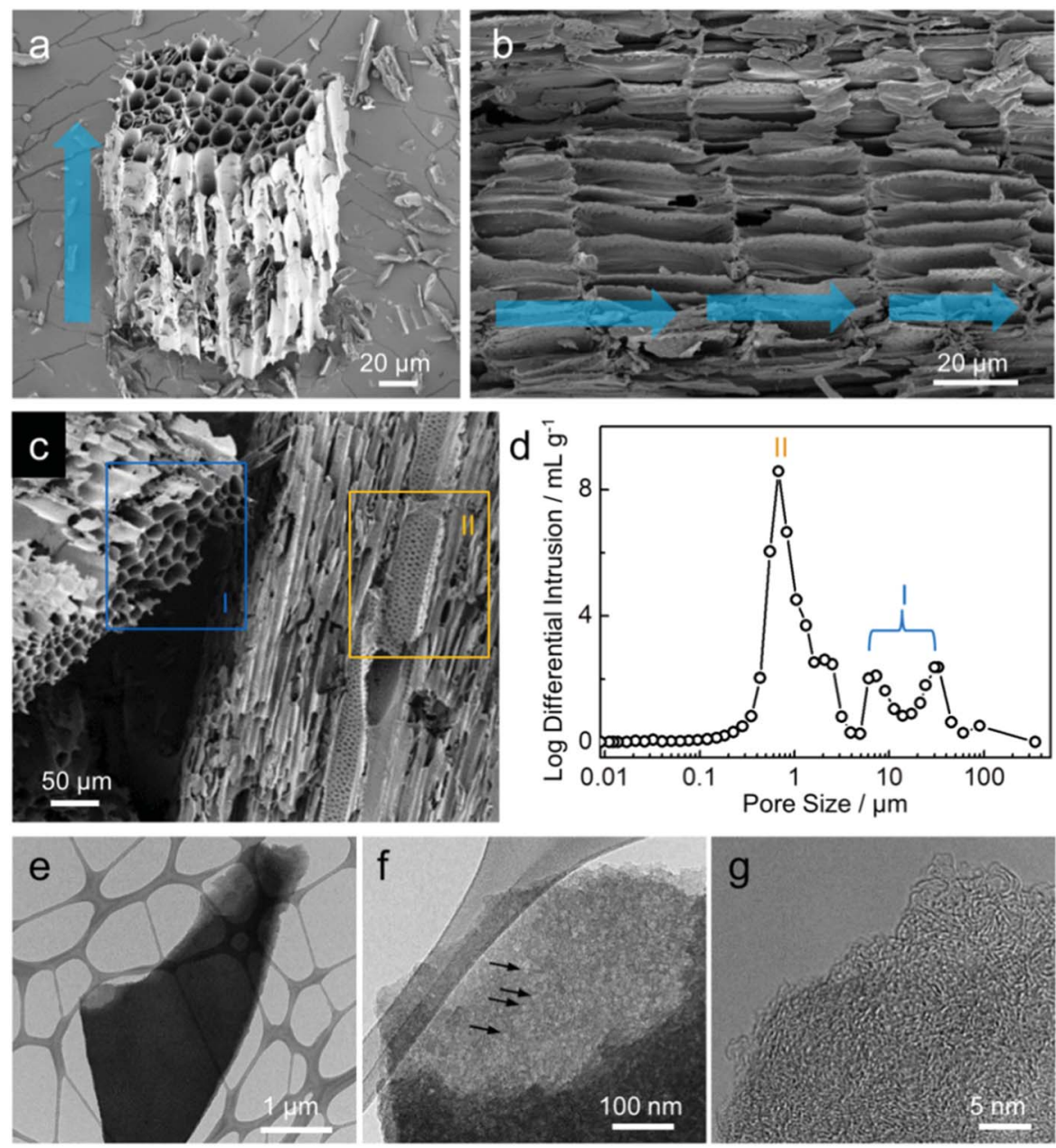

Fig. 2 Hierarchically porous carbon architecture. (a) SEM image of hemp-derived carbon with a chip-like form. (b and c) SEM images of xylemlike structure and hierarchically porous structure after activation process, respectively. Blue arrows in (b) indicate the primary flow of steam in the reactor. (d) Pore size distribution of the carbons using $\mathrm{Hg}$ intrusion porosimetry. (e-g) TEM images of hemp-derived carbon.

generates small pores on the carbon wall (yellow box II), which implies the development of macro-pores with dual pore-size distribution. Indeed, as shown in Fig. 2d, the channel-shaped pores and macro-porous walls of carbon are confirmed by pores of several tens of micrometers (I) and several micrometers (II), respectively. The structure of hemp-derived carbon was further examined using HR-TEM images, as shown in Fig. 2e-g. To conduct TEM analysis, the chip-shaped carbon was ground by hand; the corresponding carbon fragment is shown in Fig. 2e. The chip-like form breaks into small fragments of several tens of micrometers even during the sampling for SEM analysis (Fig. S2 $\dagger$ ), which confirms that the material hardness is poor enough to ground by hand. As magnification is increased, meso- and/or micro-pores are observed with different transparencies of the carbon fragments, as indicated by the black arrows in Fig. 2f, implying the abundance of nano-pores. ${ }^{28}$ In addition, Fig. $2 \mathrm{~g}$ presents that the hemp-derived carbon is composed of randomly oriented small graphitic sheets, which forms an amorphous carbon structure..$^{28,29}$ To quantitatively identify the residue materials in the hemp-derived carbon, the inorganic compositions were analyzed, and the presence of calcium (Ca), phosphorous (P), magnesium (Mg), potassium
(K), and sodium (Na) were confirmed (Table S1 $\dagger$ ). In general, the concentrations of inorganic matter in woody biomasses, including hemp, are much lower than those in algae biomass. ${ }^{30-32}$

As described above, because the carbon after activation process was obtained as a chip-shaped reaction product, handmilling in a mortar was necessary to form the powder needed for electrode fabrication. In this study, a ball-milling process for the hemp-derived carbon was designed with an intention to obtain finer powder than that from hand-milling. As shown in Fig. 3a, the crystalline structures of both natural and milled hemp-derived carbons were investigated by XRD analysis. Two peaks at $c a .23^{\circ}$ and $43^{\circ}$ (indicated by the area with diagonal lines) can be respectively assigned to the (002) and (100) reflections of typical graphite, and the considerable broadness of these peaks is indicative of the defective structure of the amorphous carbons.$^{29}$ The two peaks become sharp and narrow in case of the milled hemp carbon, implying that the ballmilling process increases the extent of graphitization in the amorphous carbon..$^{33}$ Graphitization is a process of transformation from metastable non-graphitic carbon to graphitic carbon. ${ }^{34}$ Ball-milling of amorphous carbon as well as catalytic 

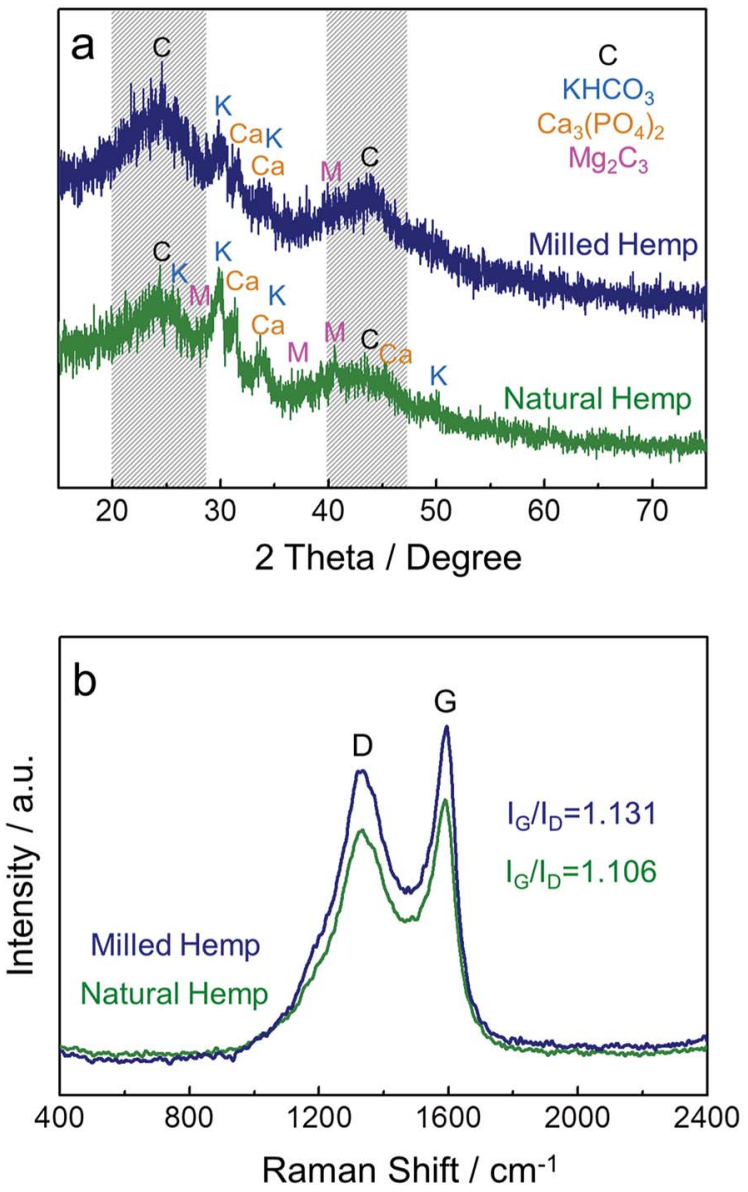

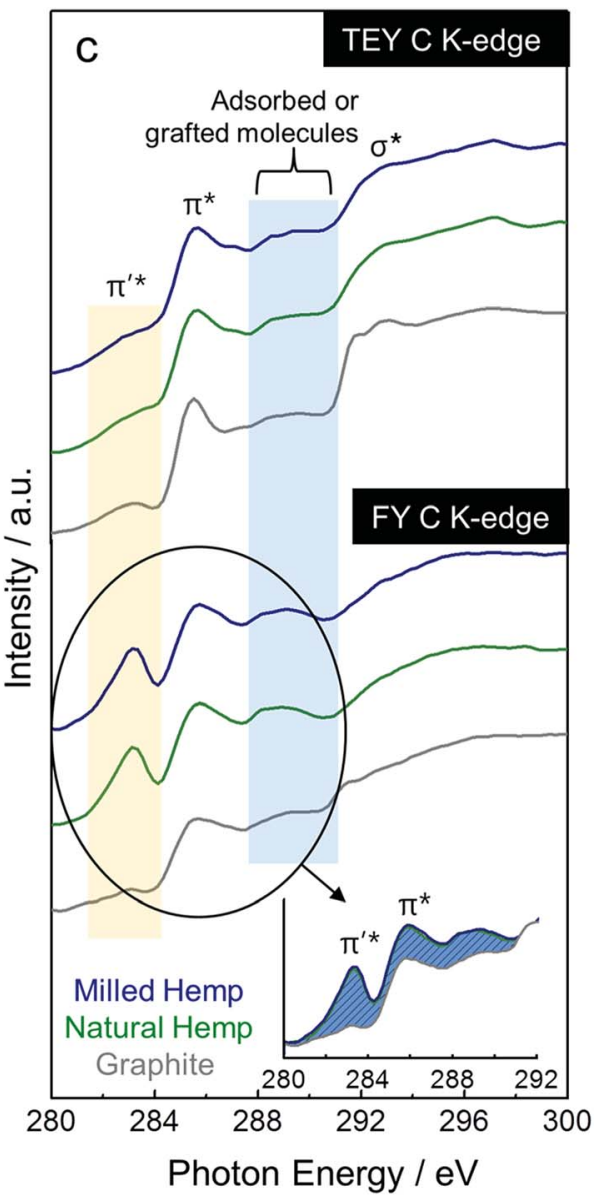

Fig. 3 Characterization of hemp-derived carbons. (a) XRD patterns, (b) Raman spectra, and (c) XANES spectra at C K-edge of natural hemp and milled hemp.

pyrolysis of carbon precursors are known strategies to obtain partially graphitic carbons. ${ }^{33,35}$ In addition to the (002) and (100) reflections, several peaks are observed in the XRD patterns of both carbons, which can be attributed to the inorganic matter such as $\mathrm{K}, \mathrm{Ca}$, P, and $\mathrm{Mg}$, as confirmed by ICP analysis. To further investigate the graphitic nature of carbon, Raman spectroscopy was performed on the hemp-derived carbons (Fig. 3b). Two major characteristic peaks at $c a .1331 \mathrm{~cm}^{-1}$ and $1592 \mathrm{~cm}^{-1}$ are observed, which correspond to the typical features of disordered graphite, i.e., crystal defects ( $D$ band) and ideal graphite (G band), respectively. ${ }^{36,37}$ The ratio of intensities of $\mathrm{D}$ and $\mathrm{G}$ band $\left(I_{\mathrm{D}} / I_{\mathrm{G}}\right.$, denoted by $\left.R\right)$ denotes the extent of graphitization. Enhanced partial graphitization in amorphous carbon during the ball-milling process is confirmed from the Raman spectra of milled hemp, as observed in Fig. $3 b^{33,35}$ Moreover, it is known that the value of $R$ is related to the size of in-plane crystallite of graphite (denoted by $L_{\mathrm{c}}$ ), as expressed by an empirical formula $L_{\mathrm{c}}=4.4 / R \cdot^{38} L_{\mathrm{c}}$ was calculated as $\mathrm{ca}$. $4.87 \mathrm{~nm}$ and $4.98 \mathrm{~nm}$ for natural hemp and milled hemp, respectively, indicating that the size of the in-plane graphite crystallite increases when the amorphous carbon undergoes the ball-milling process. Thus, it can be concluded that ball-milling of amorphous carbon from natural hemp enhances the extent of graphitization in the microcrystalline structure. Fig. $3 \mathrm{c}$ shows the C K-edge XANES spectra of the hemp-derived carbons and graphite reference, in both surface-sensitive total electron yield (TEY) and bulk-sensitive fluorescence yield (FY) modes. In TEY C K-edge spectra, all the samples, including graphite, have two main features at $c a .285 .8 \mathrm{eV}$ and $293 \mathrm{eV}$, which are assigned to the $\pi^{*}$ and $\sigma^{*}$ bands, respectively. The $\pi^{*}$ feature is typical of $\mathrm{C}=\mathrm{C}$ bond (sp2) above and below the plane, while the $\sigma^{*}$ feature is typical of in-plane $\mathrm{C}-\mathrm{C}$ bond (sp3). ${ }^{36,37}$ In addition, a wide feature centered at $c a .289 .5 \mathrm{eV}$ is observed between the $\pi^{*}$ and $\sigma^{*}$ features in the XANES spectra due to the physically adsorbed or chemically grafted molecules. ${ }^{39,40}$ Compared with TEY mode, a clear distinction of spectral profiles is observed between the hemp-derived carbons and the graphite in FY C Kedge XANES spectra. Prior to the $\pi^{*}$ feature at $c a .285 .8 \mathrm{eV}$, one new peak at $c a .283 \mathrm{eV}$, which is ascribed to $\pi^{\prime *}$, is observed only in the spectrum of the hemp-derived carbons, supporting the fact that the amorphous carbon in natural and milled hemps have a disordered structure because this peak is related with the structural defects in graphene. ${ }^{41,42}$ The inset in Fig. 3c clearly displays the peaks from adsorbed or grafted molecules, along with the $\pi^{\prime *}$ feature. Although the assignment of $\pi^{\prime *}$ feature is controversial, it is stronger in natural and milled hemps than in graphite, suggesting that it is contributed from $\mathrm{H}$ - and O-related bonds in the hemp-derived carbons. ${ }^{39,40}$ 
To analyze surface area and porosity, $\mathrm{N}_{2}$ adsorption/ desorption isotherms and pore size distribution of the hempderived carbons were investigated (Fig. 4). Both hemp carbons show a type IV pattern in their isotherms with a distinct hysteresis loop at ca. $0.5 P_{0}{ }^{-1}$, associated with the capillary condensation that takes place in meso-pores (Fig. 4a). ${ }^{43}$ The surface areas of natural and milled hemp were obtained as $c a .605 \mathrm{~m}^{2} \mathrm{~g}^{-1}$ and $526 \mathrm{~m}^{2} \mathrm{~g}^{-1}$, respectively. From the pore size distributions in Fig. $4 \mathrm{~b}$, the reason for the slightly decreased surface area in the milled hemp carbon is ascribed to the considerably decreased micro-pores after ball-milling. However, volume fraction of mesopores is significantly enhanced from $26 \%$ to $47 \%$ with ballmilling. Although further work is needed to elucidate the effect of ball-milling on porosity, ${ }^{\mathbf{4 4}}$ presently, we can confirm that the hierarchically porous structure with dual mesopore system is developed in both hemp-derived carbons. Moreover, the ballmilling process introduces increased mesopores as well as decreased micropores in the amorphous carbon.

To investigate the electrochemical activity of hemp-derived carbon electrodes, cyclic voltammetry (CV) was performed in the range of $0.01-3 \mathrm{~V}$ at a scan rate of $0.05 \mathrm{mV} \mathrm{s}^{-1}$, as shown in Fig. 5 . In electrodes of both natural and milled hemp, higher charge is involved in the first reduction process than in the first oxidation process, which is ascribed to electrolyte decomposition resulting in the irreversible formation of SEI layer at the first cathodic peak at 0.5-0.7 V. Insertion of $\mathrm{Li}^{+}$into carbon starts below $1 \mathrm{~V}$ and majority
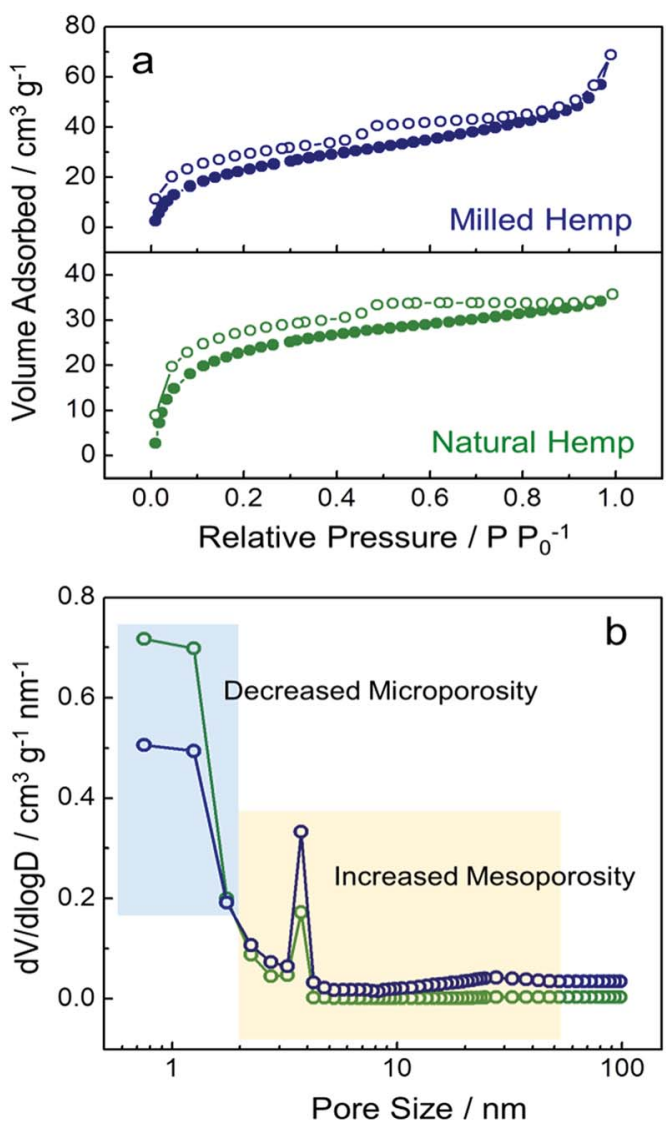

Fig. 4 Characterization of natural hemp and milled hemp. (a) $\mathrm{N}_{2}$ adsorption/desorption isotherms and (b) pore size distributions.

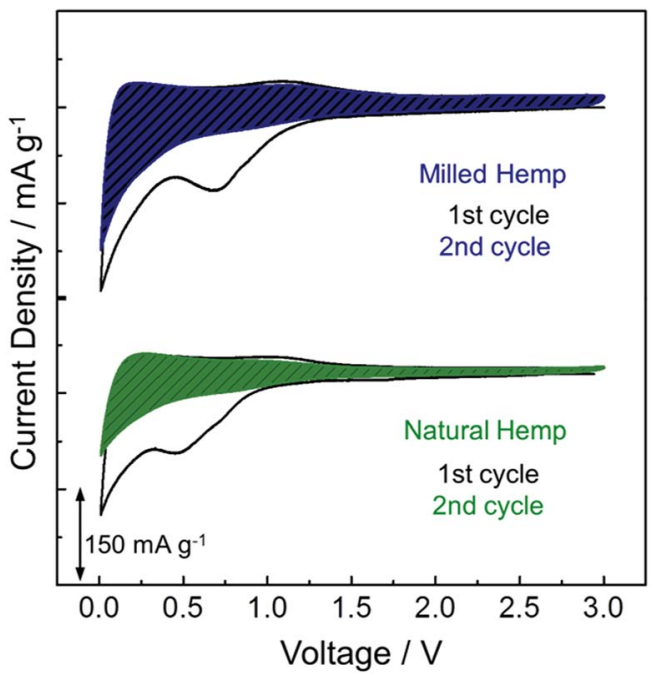

Fig. 5 Electrochemical behavior of natural hemp and milled hemp electrodes in the first two CV curves.

$\mathrm{Li}^{+}$insertion occurrs below $0.4 \mathrm{~V}$. The corresponding extraction of $\mathrm{Li}^{+}$from carbon is observed at $0.1-0.5 \mathrm{~V}{ }^{45,46}$ The electrochemical reaction above $1 \mathrm{~V}$ is understood as the discharge/charge process in electrochemical double-layer capacitors (EDLCs), which is typically similar to the electrochemical behavior of non-graphitic carbon anodes. ${ }^{47}$ Because the $\mathrm{CV}$ curve normalized by mass quantitatively represents the reactive surface area of an electrode, the wider surface area of milled hemp electrode compared with the natural hemp electrode, as distinguished by the dashed regions in Fig. 5, implies that the milled hemp electrode stores more $\mathrm{Li}^{+}$than the natural hemp electrode during the second reduction and oxidation processes.

A series of electrochemical measurements of milled hemp and natural hemp electrodes for evaluating their lithium storage properties as anode materials for LIB were conducted (Fig. 6). Fig. 6a shows the cycling performance of both electrodes at a constant current density of $300 \mathrm{~mA} \mathrm{~g}^{-1}$. Although the capacities of both electrodes degrade until 20 cycles, they exhibit stable capacity retention till the $100^{\text {th }}$ cycle. Compared with the natural hemp electrode, higher capacity is observed for the milled hemp electrode during the first 100 cycles. Charge capacity of natural hemp and milled hemp electrodes at the $100^{\text {th }}$ cycle is $190 \mathrm{~mA} \mathrm{~h} \mathrm{~g}^{-1}$ and $300 \mathrm{~mA} \mathrm{~h} \mathrm{~g}^{-1}$, respectively. The capacity of $190 \mathrm{~mA} \mathrm{~h} \mathrm{~g}^{-1}$ at the $100^{\text {th }}$ cycle with stable capacity retention indicates that natural hemp reversibly delivers 0.51 lithium per 6 carbons. For the milled hemp electrode, enhanced capacity of $300 \mathrm{~mA} \mathrm{~h} \mathrm{~g}^{-1}$ is achieved, which is better than ${ }^{48-50}$ or comparable $\mathrm{e}^{51-55}$ to that of biomass-derived carbon anodes reported in recent years. As observed, the lithium storage capacity depends on whether ball-milling was conducted or not; therefore, for optimizing the condition, the ball-milling time was extended to $3 \mathrm{~h}$. Fig. $6 \mathrm{~b}$ shows the $1^{\text {st }}$ discharge capacity as a function of ball-milling time, where discharge capacities of $611 \mathrm{~mA} \mathrm{~h} \mathrm{~g}^{-1}, 774 \mathrm{~mA} \mathrm{~h} \mathrm{~g}^{-1}$, and $596 \mathrm{~mA} \mathrm{~h} \mathrm{~g}^{-1}$ are obtained for natural hemp@0 h, milled hemp@1 h, and milled hemp@3 h electrodes, respectively. Natural hemp@0 h, milled hemp@1 h, and milled hemp@3 $\mathrm{h}$ corresponds respectively to natural 

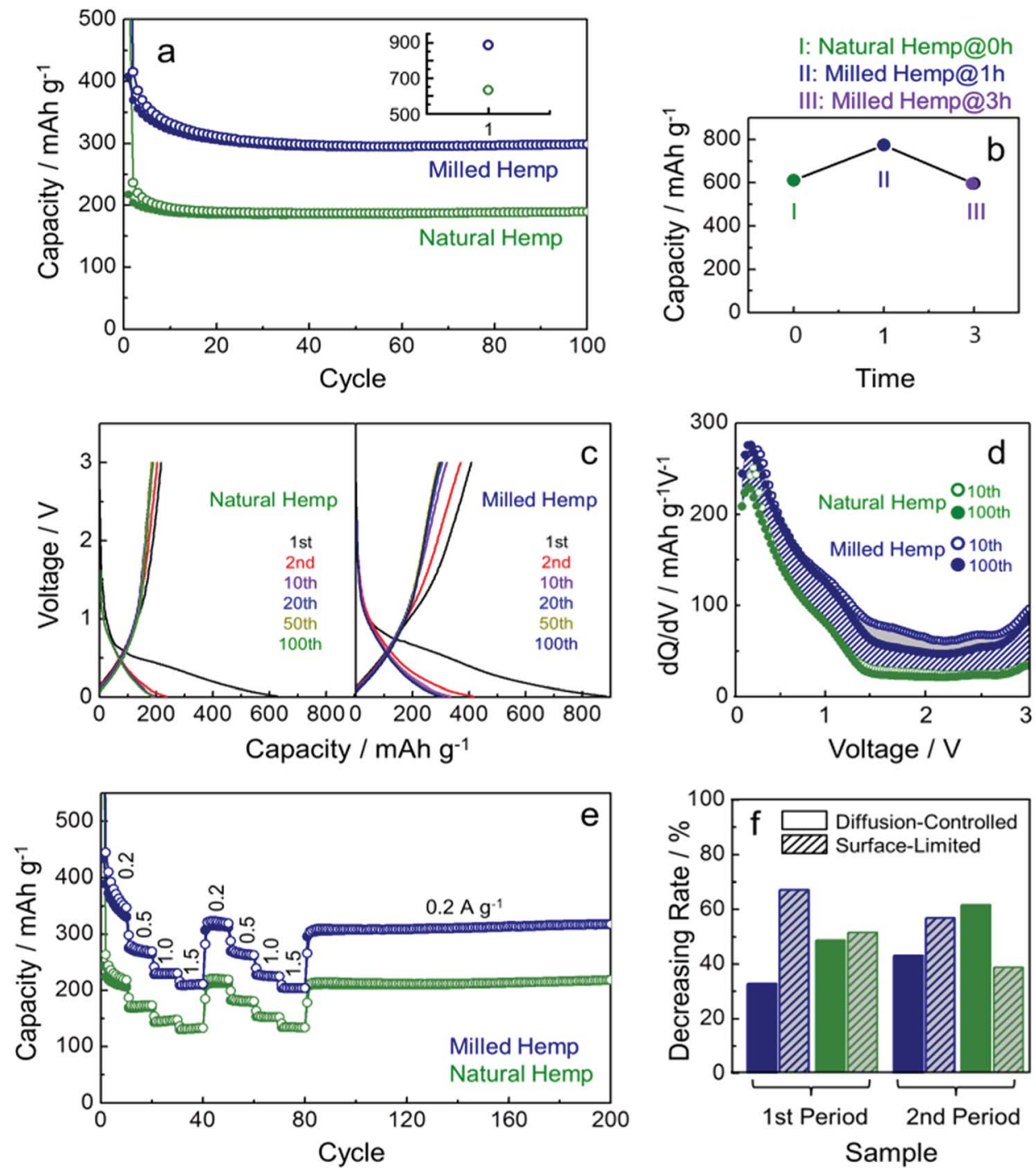

Fig. 6 Electrochemical performance of natural hemp and milled hemp electrodes. (a) Cycling performance at a current density of $300 \mathrm{~mA} \mathrm{~g}^{-1}$. The inset shows that $1^{\text {st }}$ discharge capacities of natural hemp and milled hemp are $630 \mathrm{~mA} \mathrm{~h} \mathrm{~g} \mathrm{~g}^{-1}$ and $890 \mathrm{~mA} \mathrm{~h} \mathrm{~g} \mathrm{~g}^{-1}$, respectively. (b) $1^{\text {st }}$ discharge capacity as a function of ball-milling time. (c) Voltage profiles at $300 \mathrm{~mA} \mathrm{~g}^{-1}$ after selected cycles. (d) Comparison of differential capacity profiles upon delithiation process after $10^{\text {th }}$ and $100^{\text {th }}$ cycles. Areas indicated by diagonal blue lines and grey color correspond to the area difference in differential capacity profiles between milled and natural hemp after $100^{\text {th }}$ cycle and between after $10^{\text {th }}$ and $100^{\text {th }}$ cycles for milled hemp, respectively. (e) Rate performance at various current densities from $0.2 \mathrm{~A} \mathrm{~g}^{-1}$ to $1.5 \mathrm{~A} \mathrm{~g}^{-1}$. (f) Quantitative contribution between capacitive lithium storage and diffusion-controlled intercalation. $1^{\text {st }}$ and $2^{\text {nd }}$ periods correspond to the comparison of decreasing rate between the $10^{\text {th }}$ and $40^{\text {th }}$ cycle, and the $50^{\text {th }}$ and $80^{\text {th }}$ cycle, respectively.

hemp electrode without ball-milling and milled hemp electrodes with ball-milling times of $1 \mathrm{~h}$ and $3 \mathrm{~h}$. The milled hemp@1 $\mathrm{h}$ electrode consistently yielded the best capacity during 100 cycles, as shown in Fig. S3.† Consequently, the ballmilling time was controlled at $1 \mathrm{~h}$ for subsequent experiments with the natural hemp electrode studied as the control. Voltage profiles of natural hemp and milled hemp electrodes are shown in Fig. 6c, where the first discharge/charge capacities are $630 \mathrm{~mA} \mathrm{~h} \mathrm{~g}^{-1} / 217 \mathrm{~mA} \mathrm{~h} \mathrm{~g}^{-1}$ and $886 \mathrm{~mA} \mathrm{~h} \mathrm{~g}^{-1} / 408 \mathrm{~mA} \mathrm{~h} \mathrm{~g}^{-1}$, respectively. The decrease in irreversible capacity of milled hemp is presumably due to the development of crystallinity and a densely packed structure after ball-milling. ${ }^{56-63}$ No distinct plateau is observed below $0.4 \mathrm{~V}$, which is characteristic of lithium storage in amorphous carbon with a low extent of graphitization. In addition, we can seen the slope inflection in the charge profile with a fiducial point at $\sim 1 \mathrm{~V}$, which suggests that the de-lithiation process can be separated into two parts at around $1 \mathrm{~V}^{45,46}$ as follows: (i) below $1 \mathrm{~V}(0.01-1 \mathrm{~V})$, deintercalation occurs from the interlayer of carbon by lithium diffusion and (ii) above $1 \mathrm{~V}(1-3 \mathrm{~V})$, desorption occurs at the surface of carbon via EDLCs-like capacitive behavior. ${ }^{47}$ To understand the lithium storage process in detail, differential capacity profiles ( $\mathrm{d} Q / \mathrm{d} V v s$. voltage) of natural and milled hemp electrodes after $10^{\text {th }}$ and $100^{\text {th }}$ cycles were compared (Fig. 6d). First, the wider areas below $1 \mathrm{~V}$ compared with those above $1 \mathrm{~V}$ in all the differential capacity profiles imply that lithium storage is predominant through diffusion for both electrodes, with higher contribution from the bulk than the surface. Second, 
robust bulk utilization of both electrodes is attributed to the decrease in capacity of the milled hemp electrode for capacitive lithium storage, as indicated by the grey area. Third, compared with the natural hemp electrode, the increased capacity of the milled hemp electrode originates from both reaction processes (i) and (ii), with a positive difference in overall voltage ranges (diagonal blue lines). It is suggested that the structure of milled hemp is favorable for both bulk and surface utilizations. In particular, higher capacitive lithium storage of the milled hemp electrode than the natural hemp electrode, in spite of its lower surface area, can be due to increased electrolyte-accessible surface area from mesopores instead of micro-pores clogged by SEI and side reactions. ${ }^{25,26}$ Rate capability was evaluated by increasing the current density from $0.2 \mathrm{~A} \mathrm{~g}^{-1}$ to $1.5 \mathrm{~A} \mathrm{~g}^{-1}$ and then decreasing back to $0.2 \mathrm{~A} \mathrm{~g}^{-1}$ in two consecutive cycles, as shown in Fig. 6e. For both electrodes, although the initial charge capacity gradually decreases during the first 10 cycles, stable capacity retention and good cycling stability up to 200 cycles is exhibited. Rate capacity of $\sim 130 \mathrm{~mA} \mathrm{~h} \mathrm{~g}^{-1}$ and $\sim 210 \mathrm{~mA} \mathrm{~h} \mathrm{~g}^{-1}$ are achieved for natural hemp and milled hemp electrodes, respectively at the first $1.5 \mathrm{~A} \mathrm{~g}^{-1}$ cycle, and maintained at a similar level even at the second $1.5 \mathrm{~A} \mathrm{~g}^{-1}$ cycle. In spite of continuous cycling, when the current density returns to $0.2 \mathrm{~A} \mathrm{~g}^{-1}$, capacities of both electrodes are considerably recovered, demonstrating good rate capability. Fig. $\mathrm{S} 4 \uparrow$ compares the rate capability of milled hemp with other biomass-derived carbons reported in recent years, which again confirms the excellent rate capability of hemp-derived carbon through the ball-milling process. Moreover, the contribution of diffusioncontrolled intercalation/de-intercalation and surface-limited adsorption/desorption was quantitatively investigated (Fig. 6f). The value of decreasing rate was calculated by subtracting the differential capacity profile at $0.2 \mathrm{~A} \mathrm{~g}^{-1}$ from that at $1.5 \mathrm{~A} \mathrm{~g}^{-1}$ at $1 \mathrm{~V}$, and subsequently dividing into two reaction parts, i.e., bulk (below $1 \mathrm{~V}$ ) and surface (above $1 \mathrm{~V}$ ) reactions. All of the differential capacity profiles for these calculations are displayed in Fig. S5.† As the current density increases from $0.2 \mathrm{~A} \mathrm{~g}^{-1}$ to 1.5 $\mathrm{A} \mathrm{g}^{-1}$, diffusion-controlled intercalation of the milled hemp electrode is less deteriorated compared with that of the natural hemp electrode in the $1^{\text {st }}$ period. The facile $\mathrm{Li}^{+}$diffusion into bulk in the milled hemp electrode is consistently retained in the $2^{\text {nd }}$ period. Furthermore, priority of bulk utilization in natural hemp is even reversed, which again confirms that the structure of milled hemp is favorable for bulk diffusion.

To understand the kinetics of hemp-derived carbon electrodes, GITT analysis was employed (Fig. 7), and the $\mathrm{Li}^{+}$diffusion coeff-icient $\left(D_{\mathrm{Li}^{+}}\right)$was calculated by using the following equation based on Fick's law:

$$
D_{\mathrm{Li}^{+}}=\frac{4}{\pi}\left(\frac{m_{\mathrm{B}} V_{\mathrm{M}}}{M_{\mathrm{B}} S}\right)^{2}\left(\frac{\Delta E_{\mathrm{s}}}{\Delta E_{\tau}}\right)^{2}\left(\tau \ll L^{2} / D_{\mathrm{GITT}}\right)
$$

where $m_{\mathrm{B}}, M_{\mathrm{B}}, V_{\mathrm{M}}$, and $S$ are mass, molecular weight, molar volume, and surface area, respectively, $\Delta E_{\mathrm{s}}$ is the change in steadystate cell voltage for the step in different potential range, $\Delta E_{\tau}$ is the total change in cell voltage during the current pulse for time $\tau$, and $L$ is the characteristic length. ${ }^{59}$ Fig. 7a shows the GITT curves of
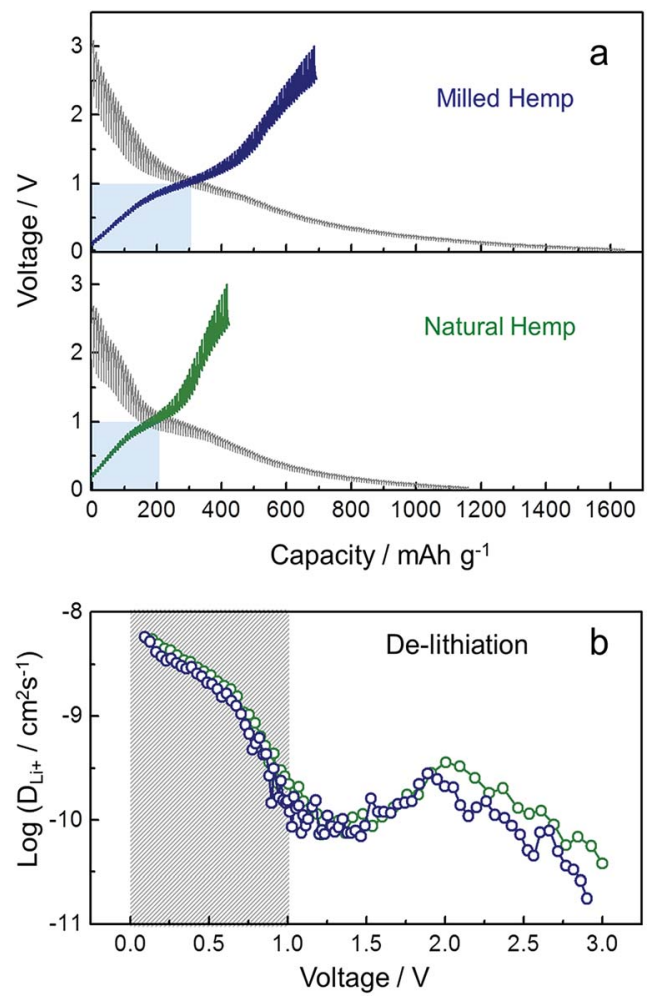

Fig. $7 \mathrm{Li}^{+}$diffusivity of natural hemp and milled hemp electrodes. (a) GITT curves of natural and milled hemp as a function of capacity in the voltage range of $0.01-3.0 \mathrm{~V}$ at $30 \mathrm{~mA} \mathrm{~g}^{-1}$. (b) $\mathrm{Li}^{+}$diffusion coefficients $\left(D_{\mathrm{Li}^{+}}\right)$calculated from GITT profile during the first charge process.

both electrodes during the first cycle. It is clearly observed that the milled hemp electrode experiences more steps compared with the natural hemp electrode, which is associated with its higher capacity. As shown in Fig. 7b, the diffusion coefficients of both electrodes consistently decrease below $1 \mathrm{~V}$; more importantly, the values are almost similar. The charge capacity of the milled hemp electrode at $1 \mathrm{~V}$ is 1.5 times higher than that of the natural hemp electrode, as shown in Fig. 7a. These observations suggest that $\mathrm{Li}^{+}$ diffusion through diffusion-controlled de-intercalation is more favorable in the milled hemp electrode. ${ }^{60,61}$ The diffusivity upon first lithiation is set aside because the first discharge is accompanied by irreversible formation of the SEI layer. As shown in Fig. S6, $\uparrow$ although the diffusion coefficients under $1 \mathrm{~V}$ for the milled hemp electrode are lower than those for the natural hemp electrode upon lithiation, the facile diffusion-controlled deintercalation in the milled hemp electrode is consistently confirmed during the second cycle. Diffusion kinetics of $\mathrm{Li}^{+}$largely depends on the crystal structure of carbon, ${ }^{61,62}$ and the enhanced diffusivity in milled hemp can result from increased partial graphitization within amorphous carbon, as confirmed by XRD and Raman analyses. A significant increase in mesoporosity of milled hemp, as observed from BET analysis, can also positively affect diffusion kinetics by decreasing the charge transfer resistance. ${ }^{63}$ Above $1 \mathrm{~V}$, diffusion coefficients of the milled hemp electrode are shown to be lower than those of the natural hemp electrode, which is probably due to the higher charge storage by 
the milled hemp electrode. Therefore, with the exception of surface-limited desorption, it is still demonstrated that the diffusion-controlled de-intercalation in the milled hemp electrode is enhanced compared with that in the natural hemp electrode.

\section{Conclusions}

Carbon from hemp stem, as a biomass precursor, was prepared using a simple, low-cost, and environment-friendly method by physical activation using only steam. The partially graphitic carbon with a hierarchically porous structure is developed in the hempderived carbon, which for the first time was directly applied as an anode material for LIB. In addition, ball-milling the hempderived carbon can control its physical properties, such as crystallinity and porosity. Consequently, enhanced graphitization and mesoporosity are simultaneously observed in the milled hemp electrode. While the natural hemp electrode itself delivers a reversible capacity of $190 \mathrm{~mA} \mathrm{~h} \mathrm{~g}^{-1}$ at a rate of $300 \mathrm{~mA} \mathrm{~g}^{-1}$ after 100 cycles, the capacity of the milled hemp electrode increases to $300 \mathrm{~mA} \mathrm{~h} \mathrm{~g}^{-1}$, along with excellent rate capability of $210 \mathrm{~mA} \mathrm{~h} \mathrm{~g}^{-1}$ even at a considerably high rate of $1.5 \mathrm{~A} \mathrm{~g}^{-1}$, suggesting that ballmilling leads to enhanced electrochemical properties for lithium storage and transport. Both the increase in diffusion-controlled intercalation/deintercalation and surface-limited adsorption/ desorption contribute to the enhanced capacity of milled hemp, which is elucidated by the advantage of enhanced graphitization and mesoporosity for lithium diffusion. This study explores the potential of hemp for its utilization in storage and transport of lithium and demonstrates that hemp-derived carbon can be a promising material for obtaining carbon electrode in energy storage devices.

\section{Conflicts of interest}

There are no conflicts to declare.

\section{Acknowledgements}

J. H. Um acknowledges support by Basic Science Research Program through the NRF (NRF-2016R1A6A3A11932369). This work was supported by the National Research Foundation of Korea (NRF) grant funded by the Korea government (MSIP) (No. NRF-2017R1A4A1015770). This study was also supported by the Institute for Basic Science (IBS) in Korea (IBS-R006-A2). Y.-H. Cho. acknowledges financial support from the Basic Science Research Program (2016R1D1A3B03934752) through the National Research Foundation of Korea (NRF), which is funded by the Ministry of Education. This research was supported by the Basic Science Research Program through the National Research Foundation of Korea (NRF), funded by the Ministry of Education, Science and Technology (NRF-2017R1E1A1A01074282).

\section{References}

1 M. Mohri, N. Yanagisawa, Y. Tajima, H. Tanaka, T. Mitate, S. Nakajima, M. Yoshida, Y. Yoshimoto, T. Suzuki and H. Wada, J. Power Sources, 1989, 26, 545-551.
2 Z. Yang, J. Zhang, M. C. W. Kintner-Meyer, X. Lu, D. Choi, J. P. Lemmon and J. Liu, Chem. Rev., 2011, 111, 3577-3613.

3 L. E. Downie, L. J. Krause, J. C. Burns, L. D. Jensen, V. L. Chevrier and J. R. Dahn, J. Electrochem. Soc., 2013, 160, A588-A594.

4 Z. Li, J. Huang, B. Yann Liaw, V. Metzler and J. Zhang, J. Power Sources, 2014, 254, 168-182.

5 P. Kalyani and A. Anitha, Int. J. Hydrogen Energy, 2013, 38, 4034-4045.

6 Y. Yao and F. Wu, Nano Energy, 2015, 17, 91-103.

7 A. A. Nunes, A. S. Franca and L. S. Oliveira, Bioresour. Technol., 2009, 100, 1786-1792.

8 C. A. Toles, W. E. Marshall and M. M. Johns, Carbon, 1997, 35, 1407-1414.

9 W. M. A. W. Daud and W. S. W. Ali, Bioresour. Technol., 2004, 93, 63-69.

10 B. Cagnon, X. Py, A. Guillot, F. Stoeckli and G. Chambat, Bioresour. Technol., 2009, 100, 292-298.

11 J. Deng, T. Xiong, H. Wang, A. Zheng and Y. Wang, ACS Sustainable Chem. Eng., 2016, 4, 3750-3756.

12 R. R. Bansode, J. N. Losso, W. E. Marshall, R. M. Rao and R. J. Portier, Bioresour. Technol., 2003, 90, 175-184.

13 J. Deng, M. Li and Y. Wang, Green Chem., 2016, 18, 48244854.

14 Y. Gao, X. Chen, J. Zhang and N. Yan, Chempluschem, 2015, 80, 1556-1564.

15 X. Chen, Y. Gao, L. Wang, H. Chen and N. Yan, Chempluschem, 2015, 80, 1565-1572.

16 P. T. Williams and A. R. Reed, J. Anal. Appl. Pyrolysis, 2003, 70, 563-577.

17 J. M. Rosas, J. Bedia, J. Rodríguez-Mirasol and T. Cordero, Ind. Eng. Chem. Res., 2008, 47, 1288-1296.

18 E. Gümüsskaya, M. Usta and M. Balaban, Bioresour. Technol., 2007, 98, 491-497.

19 H. Wang, Z. Xu, A. Kohandehghan, Z. Li, K. Cui, X. Tan, T. J. Stephenson, C. K. King'Ondu, C. M. B. Holt, B. C. Olsen, J. K. Tak, D. Harfield, A. O. Anyia and D. Mitlin, ACS Nano, 2013, 7, 5131-5141.

20 J. M. Rosas, J. Bedia, J. Rodríguez-Mirasol and T. Cordero, Fuel, 2009, 88, 19-26.

21 R. Yang, G. Liu, X. Xu, M. Li, J. Zhang and X. Hao, Biomass Bioenergy, 2011, 35, 437-445.

22 M. H. Yang, D. S. Kim, J. W. Sim, J. M. Jeong, D. H. Kim, J. H. Choi, J. Kim, S. S. Kim and B. G. Choi, Appl. Surf. Sci., 2017, 407, 540-545.

23 M. Yang, D. S. Kim, S. B. Hong, J. W. Sim, J. Kim, S. S. Kim and B. G. Choi, Langmuir, 2017, 33, 5140-5147.

24 S. Dutta, A. Bhaumik and K. C.-W. Wu, Energy Environ. Sci., 2014, 7, 3574-3592.

25 M. Broussely, P. Biensan, F. Bonhomme, P. Blanchard, S. Herreyre, K. Nechev and R. J. Staniewicz, J. Power Sources, 2005, 146, 90-96.

26 D. P. Abraham, J. L. Knuth, D. W. Dees, I. Bloom and J. P. Christophersen, J. Power Sources, 2007, 170, 465-475.

27 J. M. O. Scurlock, D. C. Dayton and B. Hames, Biomass Bioenergy, 2000, 19, 229-244. 
28 B. Campbell, R. Ionescu, Z. Favors, C. S. Ozkan and M. Ozkan, Sci. Rep., 2015, 5, 14575.

29 A. M. Stephan, T. P. Kumar, R. Ramesh, S. Thomas, S. K. Jeong and K. S. Nahm, Mater. Sci. Eng., A, 2006, 430, 132-137.

30 S. S. Kim, H. V. Ly, G. H. Choi, J. Kim and H. C. Woo, Bioresour. Technol., 2012, 123, 445-451.

31 S. S. Kim, H. V. Ly, J. Kim, J. H. Choi and H. C. Woo, Bioresour. Technol., 2013, 139, 242-248.

32 S. S. Kim, H. V. Ly, J. Kim, E. Y. Lee and H. C. Woo, Chem. Eng. J., 2015, 263, 194-199.

33 S. Zhang, Y. Cui, B. Wu, R. Song, H. Song, J. Zhou, X. Chen, J. Liu and L. Cao, RSC Adv., 2014, 4, 505-509.

34 M. Liu, L. Gan, W. Xiong, Z. Xu, D. Zhu and L. Chen, J. Mater. Chem. A, 2014, 2, 2555-2562.

35 S. Yi, Z. Fan, C. Wu and J. Chen, Carbon, 2008, 46, 378-380. 36 A. C. Ferrari and J. Robertson, Phys. Rev. B, 2000, 61, 1409514107.

37 K. N. Kudin, B. Ozbas, H. C. Schniepp, R. K. Prud'homme, I. A. Aksay and R. Car, Nano Lett., 2008, 8, 36-41.

38 D. S. Knight and W. B. White, J. Mater. Res., 1989, 4, 385-393.

39 H. K. Jeong, H. J. Noh, J. Y. Kim, M. H. Jin, C. Y. Park and Y. H. Lee, Europhys. Lett., 2008, 82, 67004.

40 B. J. Schultz, C. J. Patridge, V. Lee, C. Jaye, P. S. Lysaght, C. Smith, J. Barnett, D. A. Fischer, D. Prendergast and S. Banerjee, Nat. Commun., 2011, 2, 372.

41 A. Laikhtman, I. Gouzman, A. Hoffman, G. Comtet, L. Hellner and G. Dujardin, J. Appl. Phys., 1999, 86, 41924198.

42 Y. H. Tang, T. K. Sham, Y. F. Hu, C. S. Lee and S. T. Lee, Chem. Phys. Lett., 2002, 366, 636-641.

43 K. S. W. Sing, Pure Appl. Chem., 1985, 57, 603-619.

44 S. C. Peterson, M. A. Jackson, S. Kim and D. E. Palmquist, Powder Technol., 2012, 228, 115-120.

45 K. Tang, R. J. White, X. Mu, M. M. Titirici, P. A. Van Aken and J. Maier, ChemSusChem, 2012, 5, 400-403.
46 C. Huang, S. Zhang, H. Liu, Y. Li, G. Cui and Y. Li, Nano Energy, 2015, 11, 481-489.

47 H. Zhou, S. Zhu, M. Hibino and I. Honma, J. Power Sources, 2003, 122, 219-223.

48 J. Tang, V. Etacheri and V. G. Pol, ACS Sustainable Chem. Eng., 2016, 4, 2624-2631.

49 Q. Han, Z. Yi, F. Wang, Y. Wu and L. Wang, J. Alloys Compd., 2017, 709, 227-233.

50 R. R. Gaddam, D. Yang, R. Narayan, K. V. S. N. Raju, N. A. Kumar and X. S. Zhao, Nano Energy, 2016, 26, 346-352.

51 C. Choi, S.-D. Seo, B.-K. Kim and D.-W. Kim, Sci. Rep., 2016, 6, 39099.

52 J. Tang and V. G. Pol, Sci. Rep., 2016, 6, 20290.

53 S. W. Han, D. W. Jung, J. H. Jeong and E. S. Oh, Chem. Eng. J., 2014, 254, 597-604.

54 L. Wang, Z. Schnepp and M. M. Titirici, J. Mater. Chem. A, 2013, 1, 5269-5273.

55 X. Sun, X. Wang, N. Feng, L. Qiao, X. Li and D. He, J. Anal. Appl. Pyrolysis, 2013, 100, 181-185.

56 J. Eom and H. Kwon, J. Mater. Res., 2008, 23, 2458-2466.

57 Z. Zhang, Y. Wang, Q. Tan, D. Li, Y. Chen, Z. Zhong and F. Su, Nanoscale, 2014, 6, 371-377.

58 Z. Zhang, Z. L. Wang and X. Lu, ACS Nano, 2018, 12, 35873599.

59 W. Weppner, J. Electrochem. Soc., 1977, 124, 1569.

60 A. Pan, J. Liu, J.-G. Zhang, G. Cao, W. Xu, Z. Nie, X. Jie, D. Choi, B. W. Arey, C. Wang and S. Liang, J. Mater. Chem., 2011, 21, 1153-1161.

61 J. S. Gnanaraj, M. D. Levi, E. Levi, G. Salitra, D. Aurbach, J. E. Fischer and A. Claye, J. Electrochem. Soc., 2001, 148, A525-A536.

62 C. Garau, A. Frontera, D. Quiñonero, A. Costa, P. Ballester and P. M. Deyà, Chem. Phys., 2004, 297, 85-91.

63 S. Sun, X. Zhao, M. Yang, L. Wu, Z. Wen and X. Shen, Sci. Rep., 2016, 6, 19564. 